\title{
Burn wound healing potentials of Cynodon dactylon (L.) Pers.
}

\author{
Anand Kumar ${ }^{1}$, Anil K. Sahu ${ }^{2}$, Pankaj Kashyap ${ }^{3}$, Saraswati P. Mishra ${ }^{4}$, Deepak K. Dash ${ }^{5}$, \\ Suraj Vishwas ${ }^{6}$, Koushlesh Mishra ${ }^{7, *}$
}

1,2,3,4,6,7 Assistant Professor, ${ }^{5}$ Professor, Dept. of Pharmacy, ${ }^{1}$ University Teaching Department, Sarguja University, Ambikapur,

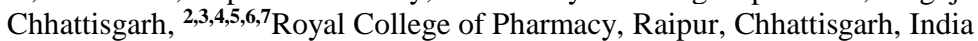

\section{*Corresponding Author: Koushlesh Mishra}

Email: koushleshmishra@gmail.com

\begin{abstract}
In this study the hydro-alcoholic extract of the plant Cynodon dactylon (L.) Pers. was undertaken to evaluate the wound healing property on Burn Wound Model and to compare the effect of the combination of hydro-alcoholic extract of Cynodon dactylon (L.) Pers. and Silver Sulphadiazine with Silver Sulphadiazine alone. Six groups are made and each group consist of 6 animals in it. Each animal of all the six group is inflicted with partial thickness burn wound. The group is numbered as Group I to Group VI. The animals in Group I are taken as control where no drug is given to them. To the Group II animals' Standard silver sulphasalazine is given. In case of group III animals, they are subjected to hydro-alcoholic extract of Cynodon dactylon. Animals in Group IV and Group V received pure ethanolic extract and aqueous extract respectively. In case of Group VI animal they are treated with standard drug as well as extract. The study mainly focuses on observing parameters like period of epithelialization and the wound contraction percentage. It is observed that the animals in the group which received both hydro alcoholic extract and sulphadiazine showed an improved burn wound contraction. In addition to it the group IV and V shows a decreased epithelialization period.
\end{abstract}

Keywords: Cynodon dactylon (L.) Pers., Epithelialization, hydro-alcoholic extract (HAE), Silver Sulphadiazine, Wound contraction.

\section{Introduction}

A wound can be described as discontinuation of tissue and leading to disruption in it due to the action of any kind of external force. Wound can be of different kinds like abrasions, lacerations, amputations, incisions, punctures, contusions and avulsions on the basis of tissue damage. Skin is the first barrier of body against the outer environment, so it is protective in nature and any damage to it has to be taken care of quickly. Healing of wound involves a coordinated flow of events which begins at injury to the tissue and end at repair of it. A well regulated processes like hemostasis, matrix synthesis, wound contraction, tissue proliferation and remodeling leads to a better wound healing. ${ }^{1}$ Tissue damage when caused by external factors like electricity, sunlight, radiation and chemicals is known as burn. Burn is one of the most common form of tissue damage that is caused in condition like building fires, flammable substances or scald and affects around 2 million persons every year. ${ }^{2}$ Among the burns, thermal burns are accountable for maximum deaths and disability. ${ }^{3}$ Small burns also need proper attention though they are not fatal in nature but for functional betterment they need same attention as fatal burns. ${ }^{4}$

Few factors like type and site of wound, disease like diabetes and health condition affects the process of wound healing greatly. Based on traditional beliefs, many medicinal plants facilitate the process of wound healing. Medicinal plants that contain constituents like ascorbic acid, tannins, terpenes and flavonoids presented better wound healing properties. As medicinal plants showed better results in healing wounds, it inspired many researchers to take up the field and try and validate the actual reason behind the result showed by the herbs. ${ }^{1}$

There are many species that grows in wild in India. Among them there is a species called Cynodon dactylon (L.) Pers. Of family Graminae/poaceae which holds an important position in ethnomedicinal practices.Locally it is called as Doob Ghas. This species is traditionally considered to have many medicinal properties. ${ }^{5}$ Cynodon plays an important role in homoeopathic system of medicine. It shows its benefits in almost all types of wound along with in the cases of bleeding and skin problems. According to Ayurveda it is beneficial in conditions like asthma, bronchitis, tumors leukoderma. ${ }^{6}$

Cynodon many active constituents like tannins, glycoside and essential oil like triticin. It also has saponins, furfural alcohol, $\beta$-ionine. ${ }^{7}$ Constituents like stigmasterol acetate, phytol are also present in the herb. ${ }^{8}$ Cuticular wax constitute substances like docosanoic acid, triacontane, docosanol. eicosanic acid, hexacosanol, octacosanol, \& tetracosanol. ${ }^{9}$

\section{Materials and Methods}

Assemblage of Plant Material: From the botanical garden of Department of Pharmacy, University Teaching Department, Sarguja University, Ambikapur, Chhattisgarh, India whole plant of Cynodon dactylon (L.) Pers. has been collected in the month of OctoberNovember 2013. The collected plant is processed by cleaning and then drying it in shades at room temperature. Care is taken to keep it away from direct sunlight. From processed plant small part of it is deposited for reference in future. 
Preparation of Extract: After collection of Cynodon dactylon (L.) Pers. it is subjected to drying and then in a grinder it is crushed to powdered form. The powder is made to pass through 120 meshes to separate fine powder from the coarse powder. The coarse powdered drug so obtained is then is utilized for the process of extraction. Hydroalcoholic solvent is used in the ratio of 70:30 for the process of extraction by a method described in Mukherjee ${ }^{9}$

Preliminary Phytochemical Screening: Standard methods are employed to carry out phytochemical screening. Presence of substances like glycosides, fixed oils, mucilage, tannins, alkaloids, flavonoids are found in the extract. ${ }^{10}$ Along with the said substances some inorganic constituents like iron, sulphur, calcium and magnesium are also present in the plant extract. ${ }^{11}$

Different extract such as hydro-alcoholic, ethanolic and aqueous are subjected to thin layer chromatography (TLC). TLC results, by the help of colour spots and Rf value, confirms the presence of constituents like saponins, flavonoids, alkaloids and tannins ${ }^{12}$
(Khandelwal 2005). ${ }^{13}$

\section{Experimental Design}

Animals: Animal experiment is conducted in accordance with CPCSEA. For the experiment male albino wistar rats of weight around 180- $200 \mathrm{~g}$ of age 23 months are taken. Then the animals are made to get accustomed to laboratory condition by letting them stay there for a week's time. The condition in which the experiment was conducted is maintained at a temperature of $22 \pm 3^{\circ} \mathrm{C}$ with a humidity of $60 \pm 5 \%$ and $12 \mathrm{hr}$ cycle of light and dark is maintained. Animals are provided with standard laboratory diet procured from Godrej Agro Food Industries, Bangalore, India and clean drinking water ad libitum is provided. Just $12 \mathrm{hrs}$ prior to experiment no food is given to the animals although water is adequately given.

Wound Study Model: In this experiment six groups are made and each group contains six animals. Following table no.1 gives brief description about each group.

Table 1: Brief discussion about experimental animals group

\begin{tabular}{|l|c|c|}
\hline S. No. & Group & Description \\
\hline 1 & I & Control \\
\hline 2 & II & Std. silver Sulphadiazine Cream (0.2 g of 5\% daily) \\
\hline 3 & III & Cynodon dactylon hydro-alcoholic extract. \\
\hline 4 & IV & Pure alcoholic (ethanolic) extract. \\
\hline 5 & V & Pure aqueous extract \\
\hline 6 & VI & The combination of the extract and the standard \\
\hline
\end{tabular}

Wound Healing Activity: To inflict a partial thickness burn wounds, firstly the animals are deprived of food overnight. Then these animals are administered with 1.5 $\mathrm{mg} / \mathrm{kg}$, i.p. of Ketamin and Xylazine to anaesthetize them. A cylinder having an opening of $300 \mathrm{~mm}^{2}$ is filled with hot molten wax with a temperature of $80^{\circ} \mathrm{C}$ and is then placed on the back of the animals ${ }^{14}$

Two parameters has been studied

1. Epithelialization Period: In this number of days is noted that is required by eschar to fall off from the wound caused by burn in such a way that it does not leave any raw wound behind.

2. Wound Contraction: Progressive change in wound area is traced in this parameter. Tracing of size of wound is done by use of a transparent paper every three days throughout the monitoring phase. The for evaluation the tracing is transferred to a graph sheet of $1 \mathrm{~mm} .^{2}$ Then by taking the initial wound area as $100 \%$, with the help of traced area, percentage of wound contraction is calculated. The formula employed for it is as follows:

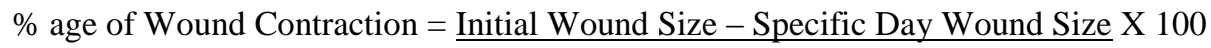

Initial Wound Size

\section{Statistical Analysis}

Mean \pm S.D is used to express all the data related to study. By taking value of $\mathrm{P}<0.005$ as significant TukeyKramer multiple comparison test and one way analyses of variance (ANOVA) were performed.

\section{Results and Discussion}

The mean period of epithelialization was observed to decrease significantly in SSD treated group $(P<$ $0.005)$. In the combination group, the result was not significant [Table 2]. From $7^{\text {th }}$ day onwards the percentage of burn wound contraction in the group that is treated with HAE increases. The percentage of wound contraction significantly increases in rat which are treated with standard $(79.6 \pm 6.5, P<0.005)$ and combination $(81.3 \pm 6.1, P<0.005)$ on $12^{\text {th }}$ day. When the results are seen on the $15^{\text {th }}$ day, all the five group treated with drug showed increase in percentage of wound contraction. The study elaborates about improvement in burn wound contraction when the animals are treated with HAE alone or with combination with SSD. The present study shows a significant improvement in burn wound contraction in the rats treated with HAE and the combination of HAE 
and SSD. As process of burn wound healing is significantly influenced by combination of HAE and SSD it can be ascertain that the HAE of Cynodon dactylon (L.) Pers. could be a better and cheaper adjuvant topical agent for faster healing. ${ }^{15}$ In the past, studies have focused on use of natural products for burn wound treatment. The wound healing property of natural products can be attributed to its antiinflammatory activity. ${ }^{16}$ The present study cannot exactly gives the insight about mechanism of prohealing of HAE of Cynodon dactylon, but it can also be due to its anti-inflammatory and antiseptic activity. ${ }^{17}$

Table 2: Effect of Cynodon dactylon (L.) Pers. extracts on wound contraction and epithelialization period

\begin{tabular}{|c|c|c|c|c|c|c|c|}
\hline \multirow{2}{*}{$\begin{array}{c}\text { Treatment }(\mathbf{N}=6) \\
\text { Formulations/ Days }\end{array}$} & & \multicolumn{5}{|c|}{$\%$ of wound contraction $($ mean $\pm \mathrm{SE})$} & \multirow{2}{*}{$\begin{array}{c}\text { Period of } \\
\text { epithelialization in } \\
\text { days (mean } \pm \text { SE) }\end{array}$} \\
\hline & & 3rd day & 6th day & 9th day & 12th day & 15th day & \\
\hline Control (Blank) & & $16.9 \pm 4.3$ & $22.1 \pm 5.6$ & $31.8 \pm 2.9$ & $39.6 \pm 3.7$ & $43.2 \pm 7.7$ & $52.8 \pm 2.2$ \\
\hline Standard (SSD) & & $11.6 \pm 3.8$ & $32.2 \pm 4.4$ & $68.7 \pm 1.9$ & $79.6 \pm 6.5$ & $94.7 \pm 2.6$ & $27.3 \pm 4.1$ \\
\hline Model-1 (HAE) & & $11.1 \pm 3.1$ & $29.6 \pm 3.9$ & $66.5 \pm 7.2$ & $74.8 \pm 3.9$ & $89.6 \pm 5.6$ & $33.5 \pm 3.4$ \\
\hline Model-2 (ALE) & & $13.4 \pm 2.8$ & $23.5 \pm 9.6$ & $42.1 \pm 7.4$ & $61.8 \pm 1.7$ & $74.2 \pm 6.1$ & $41.2 \pm 5.7$ \\
\hline Model-3 (AQE) & & $13.9 \pm 3.7$ & $22.9 \pm 2.7$ & $40.3 \pm 5.9$ & $59.2 \pm 4.5$ & $71.7 \pm 5.2$ & $42.9 \pm 6.9$ \\
\hline Model-4 (SSD+HAE) & & $11.4 \pm 2.6$ & $37.1 \pm 7.3$ & $59.8 \pm 4.9$ & $81.3 \pm 6.1$ & $93.3 \pm 3.8$ & $31.4 \pm 3.1$ \\
\hline \multicolumn{8}{|l|}{ One-way } \\
\hline ANOVA & $\mathrm{F}$ & 3.827 & 7.437 & 14.349 & 29.517 & 46.984 & 7.594 \\
\hline & $\mathrm{P}$ & $<0.060$ & $<0.021$ & $<0.005$ & $<0.005$ & $<0.005$ & $<0.005$ \\
\hline
\end{tabular}

Where: SSD- Silver Sulphadiazine, HAE- Hydro alcoholic extract, ALE- Alcoholic Extract, AQE- Aqueous Extract.

\section{Conclusion}

In the present study, observation is carried out on treatment of superficial and deep second-degree burns along with it the study showed the advantage hyaluronic acid has on silver sulphadiazine..$^{18}$ Based on the above observation it can be proposed that HAE of Cynodon dactylon can be a breakthrough development in the field of topical medication available for treatment of burns.

Conflict of Interest: The authors declare there is no conflict of interest.

\section{Acknowledgement}

Author's sincerely thanks to Dr. M. L. Naik for her professional expertise guidance, and also to Registrar of the Sarguja University for his prompt suggestions and support.

\section{References}

1. Michael G; Hiwott, Studying wound healing activity of natural products. Pharmaceutical literature and seminar II 2008;ii:1-2

2. Bingham HG, Hudson D, Popp J. A retrospective review of the burn intensive care admissions for a year. J Burn Care Rehabil. 1995;16:56-8.

3. McGill V, Kowal-Vern A, Fisher SG, Kahn S, Gamelli RL. The impact of substance use on mortality and morbidity from thermal injury. J Trauma. 1995;38:931-4.

4. Bowden ML, Thompson PD, Prasad JK. Factors influencing return to employment after a burn injury. Arch Phys Med Rehabil. 1989;70:772.

5. Mishra MP: Succession of fungi and their eco-microbial involvement in the decay of Cynodon dactylon Pers., Ph.D. Thesis: 2006;14-21.

6. Internet resources: Traditional medicinal knowledge about useful herb Doobi (Cynodon dactylon) in Chhattisgarh, India.

http://botanical.com/site/column_poudhia/111_doobi.htm 1, 12 sep 2010

7. The wealth of india, Raw materials, $1^{\text {st }}$ supplement series, CSIR, Vol. II; 331-332.

8. Wallis TE: Text book of Pharmacognosy, Plant profile for Cynodon dactylon (Bermudagrass) USDA

Plants.html, $5^{\text {th }}$ ed. Vol.-II; 243-244.

9. Mukherjee, Pulok K. Quality Control of Herbal Drugs 2002. Business Horizon: 5-34, 97, 98, 181-195, 248, 249 , 562-567.

10. Kirtikar Basu. Indian Medicinal Plants. $2^{\text {nd }}$ ed. Elsevier publications Vol. 3. p. 1042-43

11. Trease and Evans, Textbook of Pharmacognosy, Elsevier; $15^{\text {th }}$ ed. p. 204-205, 479.

12. The Ayurvedic Pharmacopoeia of India, Government of India Ministry of Health \& Family Welfare. $1^{\text {st }}$ ed. Part-1, Vol.- II, p. 62.

13. The wealth of india $2^{\text {nd }}$ supplement series, Raw materials, CSIR, Vol. 1 page no.331-332

14. Bairy KL, Somayaji SN, Rao CM. An experimental model to produce partial thickness burn wound. Indian $J$ Exp Biol. 1997;35:70-2.

15. HS Muhammad, S Muhammad. The use of Lawsonia inermis Linn (henna) in the management of burn wound infections. Afr J Biotechnol. 2005;4:934-7.

16. Gregory SR, Piccolo N, Piccolo MT, Piccolo MS, Heggers JP. Comparison of propolis skin cream to silver sulfadiazine: A naturopathic alternative to antibiotics in treatment of minor burns. J Altern Complement Med. 2002;8:77-83.

17. Rodríguez-Bigas M, Cruz NI, Suárez A. Comparative evaluation of aloe vera in the management of burn wounds in guinea pigs. Plast Reconstr Surg. 1988;81:386-9.

18. Koller J. Topical treatment of partial thickness burns by silver sulfadiazine plus hyaluronic acid compared to silver sulfadiazine alone: A double-blind, clinical study. Drugs Exp Clin Res. 2004;30:183-90. 